\title{
Antenatal risk factors in emergency caesarean sections done for fetal distress
}

\author{
Uttara Aiyer Kohli, Sanjay Singh*, Madhusudan Dey, Harpreet Kaur Bal, Atul Seth
}

Department of Obstetrics and Gynecology, Armed Forces Medical College, Pune, Maharashtra, India

Received: 21 March 2017

Accepted: 21 April 2017

\section{*Correspondence:}

Dr. Sanjay Singh,

E-mail: drsanjaysingh@gmail.com

Copyright: () the author(s), publisher and licensee Medip Academy. This is an open-access article distributed under the terms of the Creative Commons Attribution Non-Commercial License, which permits unrestricted non-commercial use, distribution, and reproduction in any medium, provided the original work is properly cited.

\begin{abstract}
Background: Fetal distress is an important indication for emergency caesarean deliveries. The objective of this study is to identify the antenatal and intrapartum risk factors in emergency caesareans done for non-reassuring fetal status and compare with patients who underwent emergency caesareans for other indications.

Methods: It was a retrospective study and data was collected from the labour room records of a tertiary care hospital. Patients undergoing emergency caesareans for fetal distress were the cases and the remaining emergency caesareans were the controls. Data was statistically analyzed.

Results: There were 5184 deliveries during this period of which, 669 were emergency caesareans. 126 (18.83\%) of these were due to fetal distress/ non-reassuring fetal status and $543(81.17 \%)$ were for other indications. Caesarean due to fetal distress accounted for $2.43 \%$ of the total deliveries. There were more primigravidae $(61.11 \%$ Vs $46.04 \%)$ in the fetal distress group (Odds Ratio 1.84, $\mathrm{p}=0.003)$. Intra uterine growth restriction (OR 5.44, $\mathrm{p}<0.0001)$ and antepartum haemorrhage mainly due to abruption (OR 11.19, $\mathrm{p}<0.0001$ ) were other important antenatal risk factors. Those with neonates of birth weight between 1.5 to $2.0 \mathrm{kgs}$ were more likely to undergo emergency caesarean for fetal distress (OR 1.78, $\mathrm{p}=0.0435$ ). The risk of a lower APGAR was higher in the fetal distress group (12.59\%). $28.34 \%$ neonates in this group required NICU admission.

Conclusions: Primiparity, intrauterine growth restriction, antepartum hemorrhage and prematurity, have shown to significantly increase the risk of emergency cesareans due to non-reassuring fetal status. We need to improve antenatal care with a goal of early detection of the above risk factors for timely institution of appropriate intervention and thus contributing to a reduction of emergency caesareans due to fetal distress.
\end{abstract}

Keywords: Abruptio placentae, Emergency caesarean, Fetal distress, Intrauterine growth restriction, Non-reassuring fetal status

\section{INTRODUCTION}

Fetal distress is a terminology used often as an indication of an emergent caesarean or operative vaginal delivery. In the past it was generally associated with an ill fetus and because of the implication of the term it could inappropriately lead to urgent delivery under general anaesthesia. However, the ACOG committee (Dec 2005) has recommended the replacement of the term fetal distress by non-reassuring fetal status followed by further description of findings-fetal tachycardia or bradycardia, repetitive variable decelerations, late decelerations and low biophysical profile. ${ }^{1}$ By specifying the indication it makes it easier to decide the mode of delivery, urgency of delivery and choice of anaesthesia. Severe preeclampsia, growth restricted fetus, postterm and oligohydramnios have been associated with abnormal/non-reassuring fetal heart tracings and caesarean deliveries. ${ }^{2}$ The availability 
of intrapartum cardiotocographic monitoring and antenatal doppler flow studies of the umbilical and other fetal vessels have improved diagnosis of the fetuses at risk to develop fetal distress. ${ }^{3}$ It has also increased intervention in the form of caesarean sections. Complications can occur unexpectedly even in the low risk patients for which presence of trained staff and facility for emergency caesarean must be available. In low resource settings, this may not be feasible. By trying to identify the antenatal and intrapartum risk factors for emergency caesarean done for fetal distress/nonreassuring fetal heart, we can attempt to identify most of these patients and ensure that they deliver at equipped centres. This study aims to identify the antenatal and intrapartum risk factors in emergency caesareans done for non-reassuring fetal status and compare with patients who underwent emergency caesareans for other indications.

\section{METHODS}

This was a retrospective cohort study. Data was collected from the labour room records of a tertiary care hospital for a period of 25 months from May 2014 to May 2016. Cases were all pregnant mothers who underwent LSCS for non-reassuring fetal status, fetal distress, fetal tachycardia, fetal bradycardia or significant decelerations, as stated in the records. Controls were all patients who underwent emergency caesarean during the same period for indications other than the above. Ethical clearance was taken from the institutional ethical committee. The data was statistically analysed and results compiled.

\section{RESULTS}

There were 5184 deliveries during the period of the study. 1736 (33.49\%) deliveries were by caesarean section; of which 669 (38.54\%) were emergency caesareans and the remaining 1067 were elective caesareans.

Of the emergency caesareans, $126(18.83 \%)$ were due to fetal distress/ non-reassuring fetal status (fetal distress group- FD). 543(81.17\%) emergency caesareans were done for other indications (non fetal distress group-NFD) (Table 1).

Table 1: Distribution of deliveries (May14-May 16).

\begin{tabular}{|lllll|}
\hline $\begin{array}{l}\text { Total } \\
\text { deliveries }\end{array}$ & $\begin{array}{l}\text { Total caesarean } \\
\text { deliveries }\end{array}$ & $\begin{array}{l}\text { Total emergency } \\
\text { caesareans }\end{array}$ & $\begin{array}{l}\text { Total emergency caesareans } \\
\text { for fetal distress }\end{array}$ & $\begin{array}{l}\text { Total emergency } \\
\text { caesareans for other } \\
\text { indications }\end{array}$ \\
\hline 5184 & $1736(33.49 \%)$ & $\begin{array}{l}669(38.54 \% \text { of the } \\
\text { total caesareans } 12.9 \% \\
\text { of the total deliveries })\end{array}$ & $\begin{array}{l}126(18.83 \% \text { of the total } \\
\text { emergency caesareans, } 7.25 \% \\
\text { of all emergency CS })\end{array}$ & $\begin{array}{l}543(81.17 \% \text { of the total } \\
\text { emergency caesareans })\end{array}$ \\
\hline
\end{tabular}

Table 2: Demographic profile of patients undergoing emergency caesarean.

\begin{tabular}{|c|c|c|c|}
\hline & $\begin{array}{l}\text { Fetal distress } \\
(n=126)(\%)\end{array}$ & $\begin{array}{l}\text { Other Indications } \\
(n=543)(\%)\end{array}$ & P value \\
\hline \multicolumn{4}{|l|}{ Age } \\
\hline$<20$ & $6(4.76)$ & $11(2.02)$ & \\
\hline $20-25$ & $53(42.06)$ & $246(45.30)$ & \\
\hline $26-29$ & $45(35.71)$ & $178(32.78)$ & \\
\hline $30-34$ & $19(15.07)$ & $87((16.02)$ & \\
\hline$\geq 35$ & $03(2.38)$ & $21(3.86)$ & \\
\hline \multicolumn{4}{|l|}{ Gravidity } \\
\hline G1 & $77(61.11)$ & $250(46.04)$ & OR $(95 \%$ CI $) 1.84(1.23-2.73) \mathrm{p}=0.003$ \\
\hline $\mathrm{G} 2$ & $28(22.22)$ & $156(28.72)$ & \\
\hline G3 & $14(11.11)$ & $97(17.86)$ & \\
\hline G4 or more & $7(5.55)$ & $40(7.36)$ & \\
\hline \multicolumn{4}{|c|}{ Period of gestation } \\
\hline$<37$ & $18(14.28)$ & $51(9.39)$ & OR $(95 \%$ CI $) 1.61(0.90-2.86) p=0.1435$ \\
\hline $37-41$ & $108(85.71)$ & $492(90.61)$ & \\
\hline
\end{tabular}

Post caesarean pregnancies with cephalo pelvic disproportion (CPD) in labour, failed trial of labour after caesarean (TOLAC), suspected scar dehiscence/tenderness, unwillingness for vaginal birth after caesarean (VBAC), associated obstetric complications accounted for $23.47 \%$ of these emergency caesareans. Labour dystocia (17.34\%) and failed inductions $(16.89 \%)$ were the other important indications. 
Malpresentations (4.18\%), Twin pregnancy related complications $(3.44 \%)$, preeclampsia/eclampsia $(3.14 \%)$ and meconium staining of liquor without fetal distress (3.14\%) were other important indications (Table 3).

Table 3: Indications for emergency caesareans other than fetal distress or non-reassuring fetal status.

\begin{tabular}{|lll|}
\hline Indications & $\begin{array}{l}\text { Number } \\
(\mathbf{n = 5 4 3 )}\end{array}$ & $\begin{array}{c}\text { \% of total emergency } \\
\text { caesareans n=669 }\end{array}$ \\
\hline Labour dystocia & 116 & 17.34 \\
\hline Deep transverse arrest & 15 & 2.24 \\
\hline Malpresentation & 28 & 4.18 \\
\hline Cephalopelvic disproportion & 15 & 2.24 \\
\hline $\begin{array}{l}\text { Post caesarean-failed TOLAC, Scar tenderness/dehiscence, with CPD in } \\
\text { labour, unwilling for VBAC or other obstetrical complications }\end{array}$ & 157 & 23.47 \\
\hline Unfavourable cervix/ Failed Induction & 113 & 16.89 \\
\hline Twins and associated complications & 23 & 3.44 \\
\hline Doppler abnormalities & 03 & 0.45 \\
\hline Uterine Anomaly & 2 & 0.30 \\
\hline Severe preeclampsia/ecclampsia with complications & 21 & 3.14 \\
\hline Meconeum stained liquor & 21 & 3.14 \\
\hline Premature rupture of membranes & 10 & 1.50 \\
\hline Oligohydramnios & 04 & 0.60 \\
\hline APH- Placenta previa/abruptio & 11 & 1.64 \\
\hline Cord Prolapse & 04 & 0.60 \\
\hline
\end{tabular}

Table 4: The antenatal and intrapartum risk factors in the fetal distress and non fetal distress groups.

\begin{tabular}{|c|c|c|c|c|c|}
\hline Comorbidities & $\begin{array}{l}\text { Fetal distress } \\
n=126\end{array}$ & $\begin{array}{l}\text { Non-fetal distress } \\
\mathrm{n}=\mathbf{5 4 3}\end{array}$ & $\begin{array}{l}\text { Risk } \\
\text { ratio }\end{array}$ & $\begin{array}{l}\text { Odds } \\
\text { ratio }(95 \% \mathrm{CI})\end{array}$ & P value \\
\hline No Comorbidity & 35 & 107 & 1.40 & $1.56(1.01-2.44)$ & 0.060 \\
\hline IUGR & 19 & 17 & 4.77 & $5.44(2.74-10.81)$ & $<0.0001$ \\
\hline GDM/Overt DM & 6 & 50 & 0.51 & $0.49(0.21-1.17)$ & 0.148 \\
\hline APH- Abruptio/Placenta Previa & 20 & 09 & 9.57 & $11.19(4.96-25.26)$ & $<0.0001$ \\
\hline Post Dated & 04 & 16 & 1.07 & $1.07(0.35-3.28)$ & 0.538 \\
\hline Rh Negative Preg & 03 & 18 & 0.71 & $0.71(0.20-2.45)$ & 0.419 \\
\hline $\begin{array}{l}\text { Hypertensive disease complicating } \\
\text { pregnancy }\end{array}$ & 15 & 66 & 0.97 & $0.97(0.53-1.77)$ & 0.920 \\
\hline IVF pregnancy & 03 & 35 & 0.36 & $0.35(0.11-1.17)$ & 0.118 \\
\hline Twins & 01 & 22 & 0.19 & $0.19(0.02-1.41)$ & 0.049 \\
\hline Post caesarean pregnancy & 17 & 153 & 0.47 & $0.39(0.23-0.68)$ & 0.0009 \\
\hline Uterine anomaly & 01 & 03 & 1.43 & $1.44(0.14-13-96)$ & 0.567 \\
\hline Oligohydramnios & 06 & 11 & 2.35 & $2.41(0.87-6.66)$ & 0.080 \\
\hline Thrombophilia (Acquired/inherited) & 03 & 06 & 2.15 & $2.18(0.53-8.84)$ & 0.231 \\
\hline Heart disease & 01 & 03 & 1.43 & $1.44(0.14-13-96)$ & 0.567 \\
\hline Hypothyroidism & 05 & 29 & 0.74 & $0.73(0.27-1.93)$ & 0.6801 \\
\hline Anemia/ $\beta$ thallessemia trait & 03 & 06 & 2.15 & $2.18(0.53-8.84)$ & 0.231 \\
\hline HIV/HBsAg infection & nil & 04 & & - & \\
\hline Bad obstetric history & 02 & 03 & 2.87 & $2.90(0.48-17.56)$ & 0.238 \\
\hline Asthma & 01 & nil & & - & \\
\hline Short stature & 02 & 03 & 2.87 & $2.90(0.48-17.56)$ & 0.238 \\
\hline Seizure disorder & Nil & 01 & & - & \\
\hline Sheehan's syndrome & Nil & 01 & & - & \\
\hline $\mathrm{IHCP}$ & 01 & 04 & 1.07 & $1.07(0.12-9.72)$ & 0.648 \\
\hline $\begin{array}{l}\text { Umbilical artery doppler } \\
\text { abnormalities }\end{array}$ & 03 & 03 & 4.30 & $4.39(0.87-22.01)$ & 0.084 \\
\hline \multicolumn{6}{|l|}{ Intrapartum } \\
\hline Meconeum in liquor & 07 & 17 & 1.77 & $1.82(0.73-4.48)$ & 0.146 \\
\hline PROM & 04 & 28 & 0.61 & $0.60(0.21-1.75)$ & 0.479 \\
\hline Malpresentation & 01 & 30 & 0.14 & $0.13(0.02-1.01)$ & 0.041 \\
\hline
\end{tabular}


The age distributions of the groups were comparable (42.06\% in FD Vs $45.3 \%$ in NFD) with maximum subjects distributed between 20-25 years. There were more primigravidae in the fetal distress group as compared to primigravidae in the non-fetal distress group $(61.11 \%$ Vs $46.04 \%)$. Odds Ratio (OR) was 1.84 with $\mathrm{p}=0.003$ making primigravida a risk factor for emergency caesarean. $14.28 \%$ patients were less than 37 weeks at the time of delivery in the FD and only $9.39 \%$ in NFD with an OR 1.61. However, $p$ value was not significant. Preterm labour may thus increase the risk of emergency caesareans for fetal distress, though statically does not appear to be significant (Table 2).

Table 4 compares the antenatal and intrapartum risk factors in the fetal distress and non-fetal distress groups.
Intra uterine growth restriction (OR 5.44, $\mathrm{p}<0.0001)$ and antepartum haemorrhage mainly due to abruption (OR $11.19, \mathrm{p}<0.0001)$ are important antenatal risk factors, which increase the risk of emergency caesareans due to fetal distress. Other factors which may increase the risk of emergency caesarean due to fetal distress are oligohydramnios (OR 2.41, $\mathrm{p}=0.080$ ), thrombophilia (OR 2.18, $\mathrm{p}=0.231$ ), anemia (OR 2.18, $\mathrm{p}=0.231$ ), bad obstetric history $(\mathrm{BOH})(\mathrm{OR} 2.9, \mathrm{p}=0.238)$, short stature (OR 2.9, $\mathrm{p}=0.23$ ), umbilical artery doppler abnormalities (OR 4.39, $\mathrm{p}=0.084$ ) and meconium stained liquor (OR 1.77, $\mathrm{p}=0.146)$.

However, the increase is not significant as per the $\mathrm{p}$ value. Post caesarean pregnancies, IVF pregnancies and Twins were less likely to have caesareans due to fetal distress as per present study.

Table 5: Neonatal outcome.

\begin{tabular}{|c|c|c|c|}
\hline Outcome & Fetal distress $n=127(1$ twin) & $\begin{array}{l}\text { Non fetal distress } n=565 \text { ( } 22 \\
\text { twins) }\end{array}$ & OR $(95 \% \mathrm{CI})$ \\
\hline \multicolumn{4}{|l|}{ Maturity } \\
\hline Term(>37wks $)$ & $108(85.03 \%)$ & $499(88.31 \%)$ & \\
\hline $\operatorname{Preterm}(<37 w k s)$ & $19(14.96 \%)$ & $66(11.68 \%)$ & \\
\hline \multicolumn{4}{|l|}{ Sex of the neonate } \\
\hline Male & $84(66.14 \%)$ & $312(55.22 \%)$ & \\
\hline Female & $42(33.07 \%)$ & $253(44.77 \%)$ & \\
\hline \multicolumn{4}{|l|}{ Birth weight (Kg) } \\
\hline$<1.5$ & $07(5.51 \%)$ & $26(4.60 \%)$ & \\
\hline $1.5-2.0$ & $17(13.38 \%)$ & $45(7.96 \%)$ & $1.78(0.98-3.23) \mathrm{p}=0.0435$ \\
\hline $2.0-2.5$ & $32(25.19 \%)$ & $98(17.34 \%)$ & \\
\hline $2.5-3.0$ & $40(31.49 \%)$ & $214(37.87 \%)$ & \\
\hline $3.0-3.5$ & $23(18.11 \%)$ & $133(23.54 \%)$ & \\
\hline$>3.5$ & $08(6.30 \%)$ & $49(8.67 \%)$ & \\
\hline \multicolumn{4}{|c|}{ Apgar score (at 5 min) } \\
\hline$<5$ & $07(5.51 \%)$ & $06(1.06 \%)$ & $5.43(1.79-16.46) \mathrm{p}=0.003$ \\
\hline $5-7$ & $09(7.08 \%)$ & $16(2.83 \%)$ & $2.61(1.12-6.06) \mathrm{p}=0.025$ \\
\hline$>7$ & $110(86.61 \%)$ & $539(95.40 \%)$ & \\
\hline IUD & 1 (fresh still birth) $(0.78 \%)$ & 04 (IUD) $(0.70 \%)$ & \\
\hline \multicolumn{4}{|l|}{ NICU admission } \\
\hline & $36(28.34 \%)$ & $54(9.55 \%)$ & $3.74(2.32-6.03) \mathrm{p}=<0.0001$ \\
\hline
\end{tabular}

Table 5 analyses the neonatal outcome of the two groups. Subjects with neonates of birth weight between 1.5 to 2.0 $\mathrm{kgs}$ were more likely to undergo emergency caesarean for fetal distress (OR 1.78, $\mathrm{p}=0.0435)$. The risk of a lower APGAR was higher in the fetal distress group. $12.59 \%$ of the 127 neonates in the fetal distress group had a low APGAR and $28.34 \%$ required NICU admission. The difference with the non-fetal distress group was significant. One fresh still birth occurred in the fetal distress group wherein the emergency caesarean had been done for abruption with fetal distress. There were four still births in the non-fetal distress group of which two patients had undergone caesarean for single fetal demise in twin pregnancy and two had undergone caesarean for abruptio placentae with intra uterine fetal demise (IUD) with maternal compromise.

\section{DISCUSSION}

Present study was a retrospective study where we compared the risk factors in emergency caesareans done for indications of fetal distress with other emergency caesareans. Our emergency caesarean rate was $12.9 \%$ of the total deliveries. The rate of emergency caesarean for fetal distress was $7.25 \%$ of all the caesareans and $2.43 \%$ of the total deliveries during this period. Caesarean rates 
as per Chauhan et al for fetal distress is $3 \%$ of all deliveries and as per Roy et al it is $6.8 \%$ (cases studied were $>36 \mathrm{wks}$ ). ${ }^{2,4}$ Gangwar et al have reported $18.02 \%$ caesarean rate for fetal distress of all caesareans. ${ }^{5}$ Although there is a rising trend of caesareans all over the world especially due to medico legal implications, present data with regards to emergency caesareans is comparable.

Analysis of the total deliveries and caesareans showed that intrauterine growth restriction and antepartum haemorrhage due to abruptio placentae significantly increase the risk of caesarean due to fetal distress. Since these two conditions are associated with preeclampsia it too may be considered a risk factor however independently it did not reflect to increase the risk in current study. Oligohydramnios, meconium stained liquor, bad obstetric history, thrombophilia, anaemia, doppler abnormalities of the umbilical artery and short stature were also risk factors for non-reassuring fetal heart leading to emergency caesareans. However, the risk was not statistically significant. Primigravidas, prematurity and low birth weight were significant risk factors in cases of fetal distress in present study. IVF pregnancies and post caesarean pregnancies tended to have a lower risk for fetal distress in this study. This could be explained by the fact that these cases are considered high risk and earlier intervention for other indications prevents caesareans being done for fetal distress.

These results were similar to a meta-analysis and review by Chauhan et al. ${ }^{2}$ They reported that among patients with moderate to severe asthma, severe hypothyroidism, severe preeclampsia, post term or fetal growth-restricted fetuses with abnormal doppler studies, the risk of caesarean delivery for fetal distress was more than $20 \%$, a prevalence at least seven times more than the general population. They found that doppler assessment of fetal vessels and amniotic fluid assessment by ultrasonography may help in assessing fetuses at risk of developing distress during labour. Intrapartum factors like induction of labour, meconium, previous cesarean and distress of second twin were also contributing factors in emergent cesareans for fetal distress in some of the studies in their analysis but results were not conclusive.

In another study titled "perinatal outcome in cesareans for fetal distress" maternal complications found associated with fetal distress were: antepartum hemorrhage, intra uterine growth restriction (IUGR), oligohydramnios, hypertensive disorders of pregnancy, cord prolapse, meconium stained liquor and second stage arrest. ${ }^{5}$ The neonatal outcome was poorer in those cases which had a risk factor as compared to those with no risk factors and worst in growth restricted babies. Maximum babies in this group required resuscitation and admission to NICU. NICU admission was $15.2 \%$ in a study by Roy et al. ${ }^{4}$ These results are similar to present study in which there were more neonates with lower APGAR and more neonatal admissions in the fetal distress group.

A study by David et al concluded that most emergent cesarean deliveries develop during labor in low-risk women and cannot be anticipated by prelabor factors and non-reassuring fetal heart rate is one of the major risk factors in these emergency cesareans. ${ }^{6}$ Even in present study $27.78 \%$ of subjects undergoing caesarean for foetal distress had no risk factors. To take care of this there is the requirement of comprehensive emergency obstetric care.

In a study from Nigeria, Akinola et al reported $8.1 \%$ incidence of caesarean due to fetal distress and found lower parity, short stature, antepartum hemorrhage and extremes of birth weight increased the risk of cesarean sections and recommended referring such women for delivery at well-equipped centers. ${ }^{7}$ In a study from England Patel et al, found similar risk factors but with a variation between institutions and concluded that a careful exploration of risk factors may allow us to identify reasons for the increasing rates of caesarean section and the marked variation between institutions. ${ }^{8}$

The strength of present study was its novelty (not many such studies are available), the population size, heterogeneity and absence of confounding factors for rate of caesarean e.g. money and insurance. The weakness was that it was a retrospective data analysis and hence was confounded by the availability of certain information in the records. Certain risk factors reported in other studies like use of prostaglandins and oxytocin and epidural analgesia have not been commented upon, in view of non-availability of sufficient data. However, a prospective study to determine the same is being done in the department.

\section{CONCLUSION}

Primiparity, intrauterine growth restriction, antepartum hemorrhage and prematurity have shown to significantly increase the risk of emergency caesareans due to nonreassuring fetal status.

Oligohydramnios, meconium stained liquor, bad obstetric history may also increase the risk, however in present study the numbers of affected subjects were insufficient to prove a significant risk. We need to improve antenatal care with a goal of early detection of the above risk factors for timely institution of appropriate intervention. This will not only result in improved maternal and neonatal outcome but also in reduction of emergency caesareans due to fetal distress.

\section{Funding: No funding sources \\ Conflict of interest: None declared}

Ethical approval: The study was approved by the Institutional Ethics Committee 


\section{REFERENCES}

1. ACOG. Inappropriate use of the terms Fetal distress and Birth asphyxia ACOG committee opinion no. 326. Americon College of Obstreticians and Gyneologists. Obstet Gynecol. 2005;106:1469-70.

2. Chauhan SP, Magann EF, Scott JR,Scardo JA, Hendrix NW, Martin JN jr. Cesarean delivery for fetal distress: rate and risk factors. Obstet Gynecol Survey. 2003;58(5):337-50.

3. Ayres-de-Campos D, Spong CY, Chandraharan E, FIGO consensus guidelines on intrapartum fetal monitoring. Cardiotocography. Int J Gynecol Obstet. 2015;131:13-24.

4. Roy KK, Baruah J, Kumar S, Deorari AK, Sharma JB, Karmakar D. Cesarean section for suspected fetal distress, continuous fetal heart monitoring and decision to delivery time. Ind $\mathbf{J}$ of Pediatrics. 2015;75(12):1249-52.

5. Gangwar R, Chaudhary S. Caesarean section for fetal distress and correlation with perinatal outcome. J Obstet Gynecol India. 2016;66(S1):177-180.
6. David C, Lagrew MD, Melissa C, Bush MD, Anna $\mathrm{M}, \mathrm{McKeown} \mathrm{MD}$ et al. Emergent (crash) caesarean delivery: Indications and outcomes. Am J Obstet Gynecol. 2006;194(6):1638-43.

7. Akinola OI, Fabamwo AO, Tayo AO, Rabiu KA, Oshodi YA, Alokha ME. Caesarean section- an appraisal of some predictive factors in Lagos Nigeria. BMC Pregnancy and Child birth 2014,14:217

8. Patel RR, Peters TJ, Murphy DJ and the ALSPAC Study Team, Prenatal risk factors for Caesarean section.Analyses of the ALSPAC cohort of 12 944women in England. Int $\mathrm{J}$ Epidemiol. 2005;34:353-67.

Cite this article as: Kohli UA, Singh S, Dey M, Bal $\mathrm{HK}$, Seth A. Antenatal risk factors in emergency caesarean sections done for fetal distress. Int $\mathbf{J}$ Reprod Contracept Obstet Gynecol 2017;6:2421-6. 